\title{
Safety in forest fire fighting action: a new radiometric model to evaluate the safety distance for firemen working with hand-operated systems
}

\author{
S. Bertoldo, L. Corgnati, A. Losso \& G. Perona \\ Dipartimento di Elettronica, Politecnico di Torino, Italy
}

\begin{abstract}
Fire event management always needs human intervention in order to extinguish forest fires. Firemen's equipment has reached high performance and safety standards but high temperatures occurring in the proximity of a forest fire may cause an increase in bodily temperature and dehydration. Therefore, it is important to identify a distance limit at which an operator can work without problems and complications due to the heat during forest fire fighting actions.

This work describes a new approach to find a safety limit for firemen. The distance limit at which the operators can work without any consequence is evaluated considering the bodily temperature increase of a man exposed for a period of time at the thermal radiations coming from the fire. The main characteristic of the model is the use of radiometry to evaluate the amount of thermal energy transferred. By varying the distance between the fire and the operator it is possible to evaluate the bodily temperature increase.

Safety distance limit is identified when human body temperature starts to be dangerous $\left(38.5^{\circ} \mathrm{C}\right)$.

In order to evaluate the distance safety value a fire model and an operator model are given. The fire model is based on the international Brown and Davis forest fire classification in order to consider some various realistic forest fire types. The fire fighter representation is established according to physiological and medical data in order to have a good representation of a real fireman.

The results of the model have been compared with the ones coming from other models used for the same purpose based on probabilistic methods and the comparison confirms the good validity of the presented model.
\end{abstract}


This fact, together with the simplicity of the model structure and the practicality of the safety distance as a reference limits allows the model to be used in future applications in order to identify and prevent some possible dangerous situations for operator engaged in forest fire fighting.

Keywords: fireman, fire fighting, forest fire, radiometry, safety distance.

\section{Introduction}

Forest fire management always needs human intervention together with the use of preventing and monitoring systems. When a forest fire is occurring, firemen are supposed to extinguish the flames in order to stop the alarm; it is important that these operators work in safety.

Men operating in forest fire affected areas are exposed to a lot of risks due to the presence of fire, smoke and gases and due to the high temperatures reached in proximity of a wildfire.

Smoke and gases may cause respiration problems and irritating actions on the mucous: a lot of protection system to prevent dangerous damages to breathing apparatus has been developed.

High temperature values reached in proximity of a forest fire may cause bodily temperature increase and dehydration. These events can be even more harmful and dangerous for fire operator's health than direct fire.

Although forest fire fighting protective clothing have reached high performance in fire protection, bodily temperature increase is still a problem for firemen using hand-operated devices and working as near as some meters from the burning edge. As a matter of fact, the optimum human body temperature is about $37^{\circ} \mathrm{C}$ while some physiological functions may be altered when it rises above $38.5^{\circ} \mathrm{C}$. Moreover, when human body reaches temperatures higher than $41.5^{\circ} \mathrm{C}$ some nerve cells may be seriously damaged (Huck [1] and Durand [2]). Therefore it is important to find out new methods to improve fire operator safety during fire fighting actions in order to prevent damages caused by heat.

Most used methods are general models analyze the different levels of thermal radiation at which a man can be exposed. They use probity harm functions. These functions have been developed and used because they better account for extremes of injury and are used by a large number of subjects bound to forest fire fighting (for example Italian firefighters). They identify some limits using thermal radiating flux as threshold values, but it is difficult and not always convenient to measure the flux of thermal radiation coming from fire.

The aim of this paper is to present a new model developed to establish a distance limit for operator in fire fighting actions. This model uses an approach based on radiometry instead of statistics. It considers the fire operator bodily temperature increase related to the distance between the operator and the front flame of the fire. The bodily temperature increase is tightly related to thermal radiations received by human body but it gives a more immediate parameter to evaluate the fireman's health when he is in action and allows him to identify some safety distance value related to different forest fire sizes. 


\section{General concepts of the model}

Heat is a form of thermal energy which can be exchanged between two bodies in three different ways: conduction, convection and irradiation. The fraction of thermal radiation in the energy balance of forest fire depends on its kind and intensity, but it can reach up than $90 \%$ (Valendik and Kosov [3]). It has been assumed that most of forest fire heat is transmitted by irradiation.

The radiometric model is made up of three basic elements: the forest fire model, the fireman model and the atmosphere layer between them. Figure 1 shows the modeled situation.

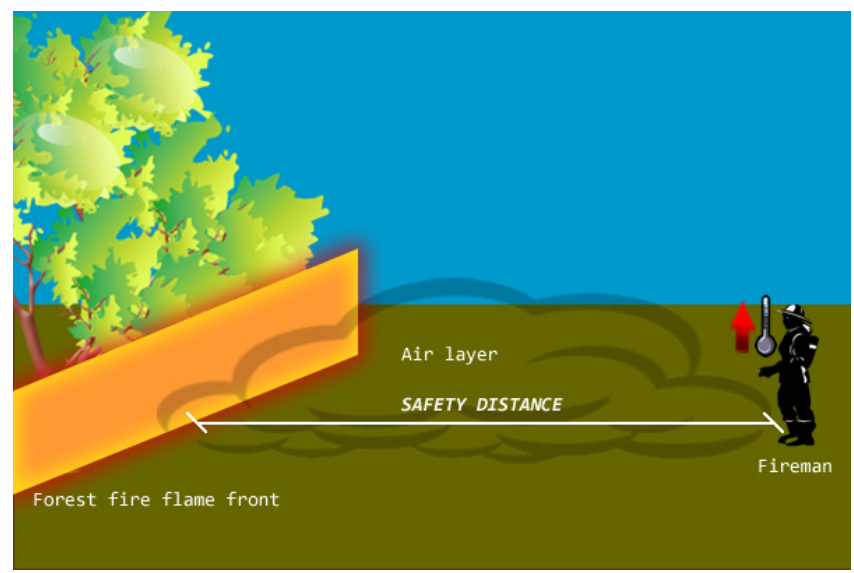

Figure 1: Graphical representation of the model.

The fire model is an infinitesimal thick wall at $\mathrm{T}_{\text {fire }}$ temperature. This wall could be rectangular or semi-circular in order to model different types of forest fire flame fronts. The fireman is supposed to have $T_{\operatorname{man}}$ temperature and his distance from the flame front is variable because it is the target value to evaluate with the radiometric model. The air layer between the two elements does not irradiate and it absorbs a very little part of radiation coming from the fire.

Thermal radiating power $\left(\mathrm{P}_{\text {inc }}\right)$ coming from the fire and reaching the man is evaluated as shown in eqn (1), where $\varepsilon_{\text {air }}$ is the air emissivity, $\mathrm{E}_{\text {inc }}$ is the thermal radiating flux and the $B S A$ is the body surface area (see paragraphs n. 3-5, for details).

$$
P_{\text {inc }}=\varepsilon_{\text {air }} \cdot E_{\text {inc }} \cdot B S A
$$

where, according to geometrical representation for rectangular forest fire flame front in Figure 2 (analog equation can be written for semi-circular wall).

$$
E_{\text {inc }}=2 \cdot\left(\frac{\sigma T_{\text {fire }}^{4}}{\pi}\right) \cdot \int_{0}^{\arctan \left(\frac{B_{M}}{z}\right)} \cos ^{2} \varphi d \varphi \cdot \int_{0}^{\arctan \left(\frac{A}{z}\right)} \cos ^{2} \vartheta d \vartheta
$$




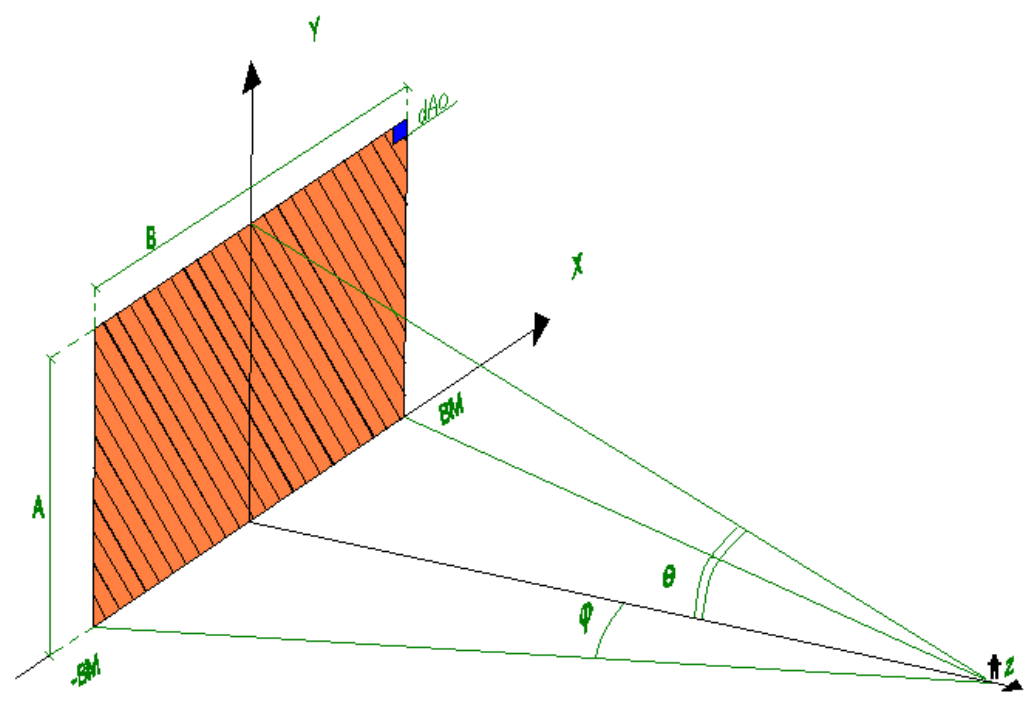

Figure 2: Geometrical representation of the model for a wall modeling a rectangular flame front. Analog representation is considered for semi-circular wall.

The man irradiated power $\left(\mathrm{P}_{\text {man }}\right)$ is evaluated as shown in eqn (3), where $\varepsilon_{\text {man }}$ is the human body emissivity, and the $B S A$ is the body surface area as before (see paragraphs n. 4 for details).

$$
P_{\text {man }}=\varepsilon_{\text {man }} \cdot \sigma T_{\text {man }}^{4} \cdot B S A
$$

A thermal radiated energy balance (Q) is then computed as in eqn (4), where $\mathrm{P}_{\text {inc }}$ is the thermal radiating power due to the fire, $\mathrm{P}_{\operatorname{man}}$ is the man irradiated power and $t_{\text {perm }}$ is the exposition time for firemen to thermal radiations, in order to evaluate the man bodily temperature increase $\Delta \mathrm{T}$ (eqn (5), $\mathrm{c}_{\mathrm{s}}$ is the human body specific heat and weight is the human body weight, see paragraph n. 4 for details).

$$
\begin{gathered}
Q=\left(P_{\text {inc }}-P_{\text {man }}\right) \cdot t_{\text {perm }} \\
\Delta T=\frac{Q}{c_{s} \cdot \text { weight }}
\end{gathered}
$$


The minimum distance value at which human body temperature reaches $38.5^{\circ} \mathrm{C}$ is determined varying the distance between the man and the fire flame front: this variation implies a consequent $\mathrm{E}_{\text {inc }}$ variation. The distance value found is the safety limit identified by the radiometric model.

\section{The fire model}

Brown and Davis forest fires classification (Brown and Davis [4]) is used to model a forest fire. This classification is one of the most used all over the world and it is useful because it gives some indications about forest fires sizes and temperatures. Moreover, a lambertian black body representation is given for the thick wall modeling the forest fire flame front.

According to the classification and to the various temperature values reached in each wooden combustion phase, the wall is supposed to be at variable temperature between $600^{\circ} \mathrm{C}$ and $1100^{\circ} \mathrm{C}$ (Fuller [5]). Different wall sizes are than estimated using both the forest fire classification and a more empiric relation evaluating the flame length (Bovio [6]), eqn (6) and eqn (7).

$$
I=273 \cdot \text { flame_heigth }^{2.17}
$$

where I is forest fire linear intensity.

$$
\text { flame_length }=0.45 \cdot I^{0.46}
$$

It is important to highlight that flame length is a particular concept tightly related to the wind: flame rises up perpendicular to the earth's surface only when there is no wind. When the wind is present they tend to tilt and stretch in the wind opposite direction, so they are longer.

By considering a rectangular wall modeling the flame front, it is quite easy to measure the flame height, but it is more difficult to do the same with the flame front extension, because of the difference between forest fires typologies. In order to give a quantitative measure of the flame front extension, flame length concept is useful in a rectangular wall model. The width of the rectangle is evaluated ideally considering the envelope of a large number of tilted flames which fill completely the whole rectangle area (Bertoldo et al. [7]).

As mentioned above, the wall thickness is supposed to be infinitesimal because it is assumed that all radiate behaviors come to the surface.

Table 1 shows the model given for each forest fire type. Two forest fire types are modeled with semi-circular wall because rectangular model would represent an excessive extended forest fire of that type. In these cases flame length concept is not necessary, because the circle radius corresponds to the flame height of the considered forest fire type. 
Table 1: $\quad$ Flame front model characteristic for different forest fire types.

\begin{tabular}{|c|c|c|c|c|c|}
\hline Fire type & $\begin{array}{c}\text { Flame } \\
\text { height }[\mathrm{m}]\end{array}$ & $\begin{array}{c}\text { Flame } \\
\text { length }[\mathrm{m}]\end{array}$ & Wall type & $\begin{array}{c}\text { Estimated } \\
\text { wall sizes } \\
{[\mathrm{m}]}\end{array}$ & $\begin{array}{c}\text { Temperature } \\
T_{\text {fire }}\left[{ }^{\circ} \mathrm{C}\right]\end{array}$ \\
\hline $\begin{array}{l}\text { Underground } \\
\text { fire }\end{array}$ & Not present & 2.97 & Rectangular & $10 \times 0.5$ & Max 400 \\
\hline Litter fire & Max 2 & Max 11.87 & Rectangular & $10 \times 2$ & \multirow{2}{*}{$\begin{array}{c}\text { From } 600 \\
\text { to } 1100\end{array}$} \\
\hline $\begin{array}{l}\text { Herbaceous } \\
\text { fire } \\
\text { Undergrowth } \\
\text { fire } \\
\end{array}$ & $\max 10$ & Max 70.97 & Semicircular & 8 & \\
\hline Crown fire & About 20 & 118.17 & Semicircular & 20 & $\begin{array}{l}\text { From } 900 \\
\text { to } 1100\end{array}$ \\
\hline
\end{tabular}

\section{The fireman model}

Fireman model comes from both radiometric and physiological considerations. It is made up of a gray lambertian body with emissivity $\varepsilon_{\text {man }}$ equal to 0.95 and temperature equals to the optimum human body temperature $\left(37^{\circ} \mathrm{C}\right)$. The human body is represented as a rectangle with its sizes evaluated by the physiological formula used for BSA calculation. In the scientific landscape there are many formulas to evaluate BSA, but Mosteller's one (Mosteller [8]) has been chosen because of its accuracy joined with its simplicity. It needs only human height and weight to evaluate the BSA and it has been considered a standard man $1.80 \mathrm{~m}$ high and $75 \mathrm{Kg}$ heavy (eqn. (8)).

$$
B S A\left[m^{2}\right]=\sqrt{\frac{h e i g h t[\mathrm{~cm}] \times \text { weight }[\mathrm{Kg}]}{3600}}
$$

Half of the result of BSA calculation gives the fraction of human body which is supposed to be exposed at radiations coming from forest fire. BSA gives total body surface area, but it has been assumed that only half of human body is exposed directly to thermal radiation. Moreover this value has been reduced by the clothing area factor $\left(\mathrm{F}_{\mathrm{cl}}\right)$ which can be calculated as a function of the thermal resistance of the clothing $\mathrm{I}_{\mathrm{cl}}$ (Rizzo et al. [9]), as shown in eqn. (9) where $\mathrm{I}_{\mathrm{cl}}$ is equal to $0.186 \mathrm{~m}^{2} / \mathrm{KW}$ (Massacci [11]).

$$
F_{c l}=1.05+0.645 \cdot I_{c l}
$$

According to the forest fire model, the thickness of the rectangle is infinitesimal because it is assumed that all radiative behaviors come to surface. 
The model "exposes" firemen to thermal radiation for 20 minutes $\left(t_{\text {perm }}\right)$ in order to represent a real fireman action with hand-operated devices near to the fire. During this time period a simple function simulate the thermal balance of human body taking into account evaporation (producing heat dissipation up to $380 \mathrm{~W} / \mathrm{m}^{2}$ during heavy work according to Holmer [10]) and breathing, which tends to decrease human body temperature.

The last data needed to evaluate the bodily temperature increase is the human body specific heat. Lots of studies demonstrate it is $3.43 \mathrm{~J} / \mathrm{g} \mathrm{K}$.

Table 2: $\quad$ Firemen model characteristics.

\begin{tabular}{|c|c|}
\hline Fireman height & $1.80 \mathrm{~m}$ \\
\hline Fireman weight & $75 \mathrm{Kg}$ \\
\hline Bodily temperature $\left(\mathrm{T}_{\operatorname{man}}\right)$ & $37^{\circ} \mathrm{C}$ \\
\hline Human specific heat $\left(c_{s}\right)$ & $3.43 \mathrm{~J} / \mathrm{g} \mathrm{K}$ \\
\hline Fireman emissivity $\left(\varepsilon_{\text {man }}\right)$ & 0.95 \\
\hline Exposure time $\left(t_{\text {perm }}\right)$ & $20 \mathrm{~min}$ \\
\hline Thermal resistance of clothing $\left(I_{c l}\right)$ & $0.186 \mathrm{~m}^{2} \mathrm{~K} / \mathrm{w}$ \\
\hline
\end{tabular}

\section{The air layer model}

The radiometric model considers an air layer between the flame front and the fireman.

Layer model is very simple because it is supposed to have only two basic characteristics: a very low radiation absorption rate and no radiative behavior. A thin-film is then used to model the air layer in order to take into account all air behaviors on the flame front model. This film wraps up the wall which represents the flame front: in this way the fire, originally modeled as a black body, becomes a gray body with emissivity equals to 0.98 .

\section{Results}

A simulation software has been implemented using MATLAB $^{\odot}$ in order to evaluate the safety distance limit and in order to test the validity of the developed radiometric model. This model uses fireman and front flame characteristics as input and gives the safety distance limit as output.

Results are shown on table 3 where found limits are linked at each forest fire type considered. 
The validation of the radiometric model is made through a comparison with three of the most commonly used fatality prediction probit models. These three models are the Eisenberg model (Eisenberg [12]), the Lees model (Lees [13]) and the Tsao-Perry model (Tsao and Perry [14]). As previously mentioned, these models identify some limits for the men with thermal radiating flux as threshold values. The radiometric model uses as reference the distance between the flame front and the fireman.

Considering the Eisenberg model (used by Italian firefighters) the reference used to test the radiometric model is the exposure limit for normally dressed people exposed for a long period of time to radiations, which corresponds to a $1.4 \mathrm{KW} / \mathrm{m}^{2}$ thermal flux value. In terms of thermal flux, this is a very safe limit value because if it used in the Eisenberg equation a value equals to 0.85 is given and this probit value corresponds to a probability of damage (burn in case of fire) on a man lower than $1 \%$. In order to do the comparison for the radiometric model also with Lees and Tsao-Perry equations, the same probit value has been used to evaluate the corresponding thermal flux.

Developing the radiometric model, a thermal balance between man and fire is computed using thermal radiant energy: it has been simple to transpose the thermal flux values, evaluated with probit model equations, in distance values directly using a table built during radiometric model simulations. In such a way it is possible to compare the safety distance limit evaluated with the here presented radiometric model with the distance at which a fireman is exposed to a certain thermal flux obtained using statistical models.

Table 3 shows this comparison.

Table 3: Radiometric model results and comparison between radiometric model and probit models.

\begin{tabular}{|c|c|c|c|c|}
\hline \multirow{2}{*}{ Fire type } & \multicolumn{4}{|c|}{ Distance limit [m] } \\
\cline { 2 - 5 } & Radiometric model & Tsao - Perry & Eisenberg & Lees \\
\hline Underground fire & $\mathbf{2}$ & $1.9-3.4$ & $1-1.9$ & $1-1.5$ \\
\hline Litter fire & $\mathbf{1 2 - 3 1}$ & $16-40.5$ & $11.5-30$ & $10-26.5$ \\
\hline $\begin{array}{c}\text { Herbaceous fire } \\
\text { Undergrowth fire }\end{array}$ & $\mathbf{3 5 - 8 7 . 5}$ & $22-57$ & $15.5-42$ & $13-36.5$ \\
\hline Crown fire & $\mathbf{1 5 9 - 2 1 9}$ & $166-228$ & $121-167$ & $107-147$ \\
\hline
\end{tabular}

Using the radiometric model, the distance limits are very similar to the ones coming from Tsao - Perry which is the most conservative and preventive of the three probit models. The results are a little different considering a comparison with Eisenberg and Lees models. Always bigger than the ones obtained by using 
the other three statistical model. That is a consequence of the approximations done to represent the elements of the model, especially with regard to air layer between the man and the flame front and with regard to fireman body model. Concerning thermal exposure, it means that other model, different from TsaoPerry, are more optimistic and they allow people to be exposed to thermal radiation for a longer period of time or to be exposed to a greater thermal flux on equal exposure time.

Anyway the goodness of the radiometric model is proved if it is considered as a preventive model which improves firemen safety in fire fighting operations without specific clothes and using hand-operated devices.

\section{Conclusions and outlooks}

A new model to evaluate a safety distance for firemen in operations with hand operating systems has been proposed. The model uses a radiometric approach to evaluate the safety distance limit. Considering the approximations, results show us the model validity if it is compared with the statistical and probabilistic model methods.

The goal of this model is the simplicity joined with the immediate reading reference values given and it is very useful to prevent men from damages caused by high temperature reached in proximity of a wooded fire.

The future target will be to release a more complete model of the layer between the man and the fire, in order to consider the absorption of the air layer, and a more precise model of real part of the body surface area directly exposed to thermal radiations.

Moreover, it will be possible to use this radiometric model to evaluate other distance limits regarding real firemen equipped with special clothing, and to evaluate, not only a bodily temperature increase, but also the distance at which burns and more serious damages can happen on human skin.

\section{References}

[1] Huck J., Physiologic response of fire fighters wearing structural and hazmat protective clothing, Second Annual Conference on Protective Clothing, Clemson University, May 1988.

[2] Durand R., Thermoregulatory Demands During Firefighting Activities High Heart Rate and Body Temperatures Increase Strain On Body, special contribute to Firehouse.com.

[3] Valendik E.N., Kosov I. V., Effect of thermal radiation of forest fire on the environment, Sibirskii Ekologicheskii Zhurnal, Vol. 15, No. 4, pp. $517-$ 523, 2008.

[4] A.A. Brown, K.P. Davis - Forest Fire: control and use. McGraw -Hill, New York, 1973.

[5] Fuller M., An introduction to wildland fire behaviour, management firefighting and prevention, Wiley Nature Editions, 1991. 
12 Modelling, Monitoring and Management of Forest Fires III

[6] Bovio G., Come proteggersi dagli incendi boschivi. Regione Piemonte, 1988.

[7] Bertoldo S., Corgnati L., Perona G., Un nuovo modello radiometrico per l'identificazione di hot spot di incendi boschivi e come strumento di valutazione delle performance dei sensori in abienti ad orografia complessa, Atti della 15a Conferenza Nazionale ASITA, pp. 325-334, Federazione ASITA, 2011.

[8] Mosteller RD., Simplified calculation of body-surface area, pp. 317-1098, 1987.

[9] Rizzo G., Frazitta G, Cannstraro G., Algorithm for the calculation of the mean projected area factors of seated and standing persons, Energy and buildings, Vol. 17, pp. 221-230, 1991.

[10] Holmer I., Protective clothing in hot environment, Industrial Health, Vol. 44, pp. 404-413, 2006.

[11] Massacci G., Dispense del corso di sicurezza del lavoro e difesa ambientale 2, Fascicolo 10, Microclima e benessere termico negli ambienti di lavoro, Università degli studi di Cagliari, Facoltà di Ingegneria, A. A. 2006/07.

[12] Eisenberg N. A. et al., Vulnerability model. A simulation for assessing damage resulting from marine spills, 1975.

[13] Lees F. P., Loss prevention in process industries, Butterworth Einemann, 1994.

[14] Tsao C. K., Perry W.W., Modifications to vulnerability model. A simulation for assessing damage resulting from marine spills (VM 4), 1979. 